\title{
Pustular psoriasis: pathophysiology and current treatment perspectives
}

\author{
This article was published in the following Dove Press journal: \\ Psoriasis: Targets and Therapy \\ 12 September 2016 \\ Number of times this article has been viewed
}

\section{Katie E Benjegerdes' \\ Kimberly Hyde ${ }^{2}$ \\ Dario Kivelevitch ${ }^{3}$ \\ Bobbak Mansouri ${ }^{1,4}$}

'Texas A\&M Health Science Center College of Medicine, Temple, ${ }^{2}$ Texas A\&M Health Science Center College of Medicine, Round Rock, ${ }^{3}$ Division of Dermatology, Baylor University Medical Center, Dallas, ${ }^{4}$ Department of Dermatology, Scott and White Hospital, Texas A\&M Health Science Center College of Medicine, Temple, TX, USA
Correspondence: Bobbak Mansouri Department of Dermatology, Scott and White Hospital, Texas A\&M Health Science Center College of Medicine, 409 W Adams Ave, Temple, TX 7650I, USA Tel +l 4092547423724

Fax + I 4092547423776

Email bobbak.mansouri@gmail.com
Abstract: Psoriasis vulgaris is a chronic inflammatory disease that classically affects skin and joints and is associated with numerous comorbidities. There are several clinical subtypes of psoriasis including the uncommon pustular variants, which are subdivided into generalized and localized forms. Generalized forms of pustular psoriasis include acute generalized pustular psoriasis, pustular psoriasis of pregnancy, and infantile and juvenile pustular psoriasis. Localized forms include acrodermatitis continua of Hallopeau and palmoplantar pustular psoriasis. These subtypes vary in their presentations, but all have similar histopathologic characteristics. The immunopathogenesis of each entity remains to be fully elucidated and some debate exists as to whether these inflammatory pustular dermatoses should be classified as entities distinct from psoriasis vulgaris. Due to the rarity of these conditions and the questionable link to the common, plaque-type psoriasis, numerous therapies have shown variable results and most entities remain difficult to treat. With increasing knowledge of the pathogenesis of these variants of pustular psoriasis, the development and use of biologic and other immunomodulatory therapies holds promise for the future of successfully treating pustular variants of psoriasis.

Keywords: psoriasis, pustular psoriasis, generalized pustular psoriasis, von Zumbusch, impetigo herpetiformis, acrodermatitis continua of Hallopeau, palmoplantar pustulosis, biologic

\section{Introduction}

Psoriasis vulgaris is a chronic inflammatory condition associated with significant morbidity and mortality. ${ }^{1}$ Plaque psoriasis is the most common form of psoriasis vulgaris and classically presents as discrete, erythematous plaques with an overlying silvery scale on extensor surfaces. Psoriasis can also involve the nails and scalp or progress to erythroderma. Less common clinical presentations include guttate, inverse, or pustular psoriasis. ${ }^{2}$

Within the classification of pustular psoriasis, the disease is further subdivided into generalized pustular psoriasis (GPP) and localized pustular psoriasis. GPP includes acute GPP, pustular psoriasis of pregnancy, and infantile/juvenile pustular psoriasis. Localized pustular psoriasis includes palmoplantar psoriasis and acrodermatitis continua of Hallopeau $(\mathrm{ACH}) .^{2-5}$

All variants of pustular psoriasis have similar presentations in that they involve an eruption of superficial pustules in a given distribution, typically with an erythematous base or studded on a background of erythema. As such, histopathologic examination of all variants reveals parakeratosis, extensive mononuclear and neutrophilic inflammatory infiltrate in the epidermis, and epidermal edema and hyperplasia. ${ }^{5-10}$ Spongiform 
pustules of Kogoj and hyperplasia of suprapapillary capillaries may be seen. ${ }^{5,11-13}$ Munro's microabscesses typical of plaque psoriasis are frequently seen as well. ${ }^{13}$

\section{Generalized pustular psoriasis Acute GPP (von Zumbusch type) History}

Acute GPP, also known as von Zumbusch type, is a dermatologic disease for which classification is somewhat debated. ${ }^{14}$ Sixty-five percent of cases of acute GPP occur in patients with a prior diagnosis of psoriasis vulgaris, ${ }^{15,16}$ and historically, acute GPP has been presented as a variant of plaque psoriasis. However, recent research indicates that acute GPP and plaque psoriasis are genetically distinct conditions without a common pathophysiologic mechanism. ${ }^{17}$

\section{Epidemiology/presentation}

Acute GPP is associated with significant morbidity and in some cases, mortality, especially in the absence of appropriate treatment. ${ }^{16}$ It is characterized by generalized sterile pustule formation with widespread inflammation and erythema (Figure 1). The pustules often expand and coalesce, forming lakes of pus. ${ }^{1}$ Acute GPP is often associated with systemic symptoms such as fever, chills, malaise, anorexia, nausea, and severe pain..$^{1,18}$ Other physical findings may be present with acute GPP, such as subungual pustules and geographic tongue. ${ }^{1}$ The systemic nature of the disease is reflected in the laboratory abnormalities found in many patients, including hypocalcemia and hypoalbuminemia, as well as in the possible presence of polyarthralgias and neutrophilic cholangitisinduced cholestasis..$^{19,20}$

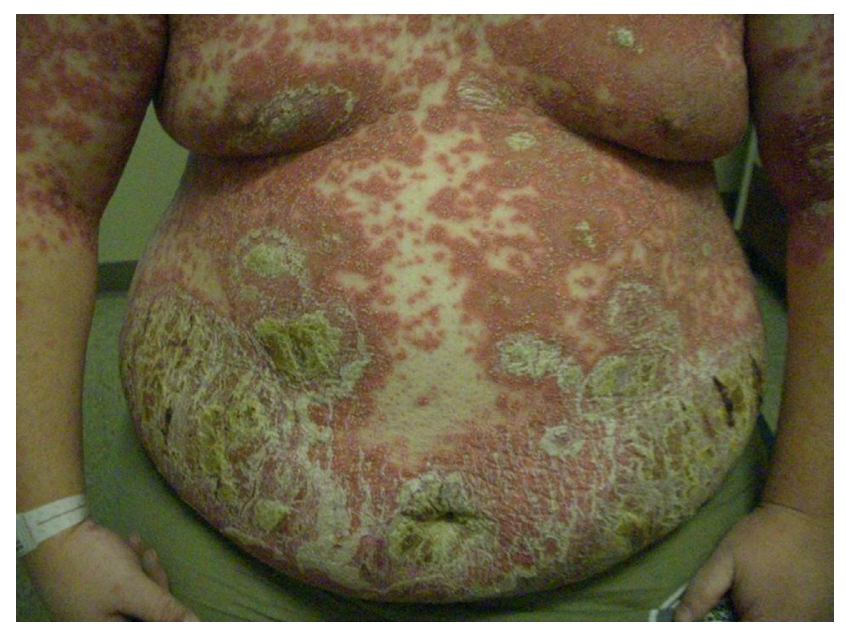

Figure I Generalized pustular psoriasis.

Notes: Innumerable pustules studded on a background of erythematous plaques on the chest, abdomen, and upper arms. Some areas of pustules have coalesced into large plaques of crust on the lower abdomen. Used with permission of Professor Alan Menter, Baylor University Medical Center.
The mean age at onset of acute GPP is 40.9 years, with no difference in onset related to the presence or absence of a prior history of psoriasis vulgaris. ${ }^{15}$ Two separate studies have found a higher incidence of acute GPP in male, with an incidence of $57 \%-62 \%{ }^{16,20}$ The majority of studies, however, found a predominance in female, ranging from 53\% to $73 \% .^{15,19,21,22}$ Females do tend to have a nonstatistically significant earlier onset compared to male, with a mean age of 39.4 years compared to 44.3 years. ${ }^{15}$

\section{Pathophysiology}

Various precipitating factors have been reported to trigger or flare acute GPP, including corticosteroid use and withdrawal, pregnancy (also termed impetigo herpetiformis), upper respiratory tract infections, stress, nonsteroidal anti-inflammatory drugs, terbinafine, ustekinumab, tumor necrosis factor (TNF)- $\alpha$ inhibitors, and methotrexate. ${ }^{15,23}$

The use and subsequent withdrawal of systemic corticosteroids is an important cause of an eruption of acute GPP. ${ }^{24}$ The use of systemic corticosteroids leads to inhibition of the inflammatory system. Acute withdrawal of systemic corticosteroids can lead to an acute inflammatory process acting as a trigger for acute GPP. ${ }^{12}$ In one retrospective study of 102 patients with acute GPP, systemic glucocorticoids were determined to be a likely trigger for the onset of the disease in $44 \%$ of patients. ${ }^{15}$

Upper respiratory tract infections, and other infections, can also lead to an acute activation of neutrophils, which may act as a trigger for the onset of acute GPP. ${ }^{12}$ Choon et $\mathrm{l}^{15}$ reported that acute infections have been found to be a trigger or exacerbating factor in $16 \%$ of acute GPP patients, with $38.5 \%$ of patients exhibiting positive antistreptolysin antibodies. Ustekinumab, a monoclonal antibody against the p40 subunit common to interleukin (IL)-12 and IL-23, which is commonly used for the treatment of plaque psoriasis, can lead to a change in a patient's psoriasis morphology from plaque psoriasis to pustular psoriasis and can also cause new or worsening acute GPP. ${ }^{25,26}$ Other drugs, such as terbinafine and methotrexate, may also serve as triggers for acute GPP as a form of drug-specific allergic reactions, which can often be confirmed with patch tests. ${ }^{12,27}$

GPP may also be strongly associated with certain predisposing genetic factors. In a study of nine Tunisian families with GPP, a genetic mutation in the IL36RN gene leading to an aberrant IL-36 receptor antagonist (IL-36RA) was discovered in all affected patients in the study and was noted to cause an unstable IL-36RA protein with decreased affinity for its receptor. ${ }^{28}$ The mutation in the IL-36RA protein also 
led to an increase in proinflammatory cytokines. ${ }^{29}$ GPP in the setting of this specific genetic mutation has been termed "DITRA" or "deficiency in IL-36RA". ${ }^{30}$ The IL36RN gene codes for the IL-36RA molecule. This molecule inhibits the effects of multiple IL-36-associated cytokines, including IL-36 $\alpha$, IL-36 $\beta$, and IL-36 $\gamma$, all of which are members of the IL-1 cytokine family. ${ }^{31}$ These and numerous other cytokines in the IL-1 cytokine family are abundantly expressed in skin. ${ }^{32}$ When the IL-36R is bound by an agonistic cytokine in the IL-1 family, downstream proinflammatory pathways are activated. ${ }^{30}$ However, the inhibitory effect of IL-36RA competes with the agonistic IL-36 cytokines for attachment to IL-36R. ${ }^{30}$ Antagonism of the IL-36R with the IL-36RA results in an anti-inflammatory milieu by the inhibition of the nuclear factor kappa-light-chain-enhancer of activated $B$ cells and mitogen-activated protein kinase signaling pathways and the activation of their downstream inflammatory pathways..$^{30,31,33}$ Hence, without the anti-inflammatory effect of functional IL-36RA (as is seen in mutations of the $I L 36 R N$ gene), IL-36 is uninhibited in its ability to enhance the production of proinflammatory mediators, leading to the unopposed effects of IL-36 on nuclear factor kappa-lightchain-enhancer of activated B cells and mitogen-activated protein kinase inflammatory pathways. ${ }^{28,32,34}$

IL-36R can be located on a number of cells found in the skin, including dendritic cells, keratinocytes, and monocytes. ${ }^{30}$ IL-36R activation can also stimulate type 1 T-helper cells $\left(\mathrm{T}_{\mathrm{H}} 1\right.$ cells) in humans. Activation of IL-36R within these cells leads to activation of inflammation within the skin and development of the clinical features of inflammatory skin conditions, specifically GPP.

GPP and its important genetic association with IL-36RA deficiency has also been shown to exhibit a gene dosage effect. In individuals found to have only monoallelic mutations in the IL36RN gene, the onset of GPP is significantly delayed. ${ }^{31}$ This delay is perhaps due to these heterozygous patients requiring longer or more intense exposure to the precipitating factors associated with GPP in order to develop the disease. ${ }^{31}$ However, despite the evidence of a strong correlation between IL-36RA deficiency and GPP, not all patients with GPP have evidence of IL-36RA mutations.

Another study regarding the various possible genetic mutations associated with GPP was conducted in nine children from six families who presented with neonatal sterile osteomyelitis, periostitis, and generalized pustulosis. This study discovered the condition present in these children was linked to a genetic mutation involving $I L 1 R N$, which encodes the IL-1 receptor antagonist. The IL-1 receptor antagonist inhibits IL- $1 \alpha$ and IL- $1 \beta$, which are proinflammatory cytokines. A mutation in the gene ILRN leads to the absence of IL-1 receptor antagonist protein, resulting in uninhibited inflammatory actions of IL- $1 \alpha$ and IL- $1 \beta .{ }^{35}$

\section{Treatment}

While the treatment of chronic plaque psoriasis has become relatively effective in the era of biologic therapies, treatment of pustular forms of psoriasis remains an area lacking in research, in part due to the rarity of the disease. ${ }^{36}$ This dearth of research has led to lack of universally accepted, evidence-based guidelines for treatment and management of pustular forms of psoriasis and off-label use of many medications. ${ }^{37}$ Evaluation of the various treatment options available has yielded limited guidance on selecting therapies for such patients. ${ }^{18}$ Therapeutic choices for pustular psoriasis are most often based on severity, extent of involvement, and disease morphology. ${ }^{18}$

Acute GPP has proven to be, like many psoriasis variants, a difficult disease to treat. Guidelines published in 2012 by the Medical Board of the National Psoriasis Foundation recommend acitretin, cyclosporine, or methotrexate to be the first-line therapies for acute GPP (Table 1). ${ }^{18}$ Severe and extensive disease is likely to most effectively be treated with infliximab or cyclosporine, given the quicker onset of action with these drugs. ${ }^{18}$ Infliximab, a TNF- $\alpha$ inhibitor, has a uniquely rapid onset of therapeutic effect. One study described the efficacy in nine of ten patients with acute GPP who experienced results within 24 hours to 7 days of the first treatment. ${ }^{38} \mathrm{~A}$ similar study showed an improvement in all patients with acute GPP at 2 weeks following initiation of infliximab therapy, with disappearance of pustules in all enrolled patients and continued remission at 30 weeks. $^{38,39}$

The recommended second-line therapies include adalimumab, etanercept, psoralen plus ultraviolet-A (PUVA) phototherapy, topical corticosteroids, topical calcipotriene, and topical tacrolimus, or combination therapy for recalcitrant disease (which includes a first-line oral systemic agent plus a biologic agent such as adalimumab or etanercept). ${ }^{18,40-45}$ The initial use of infliximab to treat severe acute disease, followed by treatment with etanercept has also been reported to be successful. ${ }^{18}$ The use of systemic steroids is generally avoided when treating pustular psoriasis, given the risk of worsening disease following withdrawal of the medication. If necessary, however, they may be used in circumstances in which other therapeutic options are not available. ${ }^{43}$

In recent years, additional reports of biologic therapies targeting IL-1, IL-12/23p40, and IL-17A have been reported. 
Table I Treatment of generalized pustular psoriasis

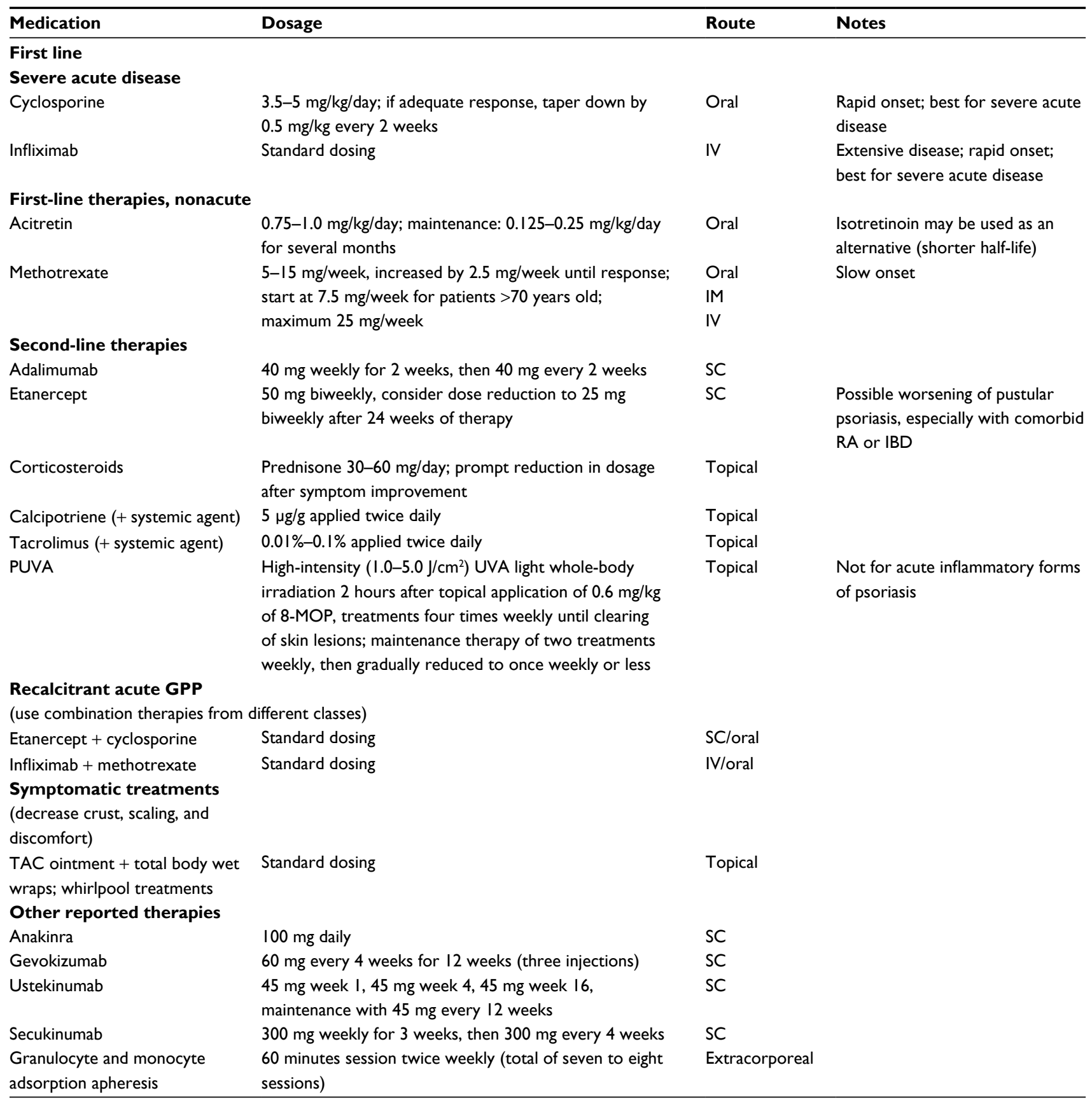

Abbreviations: GPP, generalized pustular psoriasis; IM, intramuscular; IV, intravenous; PUVA, psoralen plus ultraviolet-A; SC, subcutaneous; UVA, ultraviolet-A; 8-MOP, 8-methoxypsoralen; RA, rheumatoid arthritis; IBD, inflammatory bowel disease; TAC, triamcinolone acetonide.

Anakinra, an IL-1 receptor antagonist, has been described to successfully treat GPP, and gevokizumab, an IL-1 $\beta$ inhibitor, showed some promise in treating two patients with GPP. ${ }^{46-48}$ Ustekinumab, a monoclonal antibody targeted against the shared p40 subunit of IL-12 and IL-23, has been used to successfully treat GPP, as well. ${ }^{37}$ Most recently, the biologic therapy secukinumab, an IL-17A inhibitor, has shown promising ability to provide rapid resolution of symptoms in the treatment of GPP. ${ }^{49}$
The unique treatment of GPP with granulocyte and monocyte adsorption (GMA) apheresis has also been described. Because the immunopathogenesis of GPP involves activated neutrophils and monocytes, GMA provides an effective treatment that involves removal of activated granulocytes and monocytes from the patient's circulation, resulting in improvement of acute GPP. ${ }^{14,50,51}$

Despite reports of successful treatment of acute GPP with various biologic agents, the literature supporting the 
treatment of acute GPP is weak. ${ }^{18}$ Further exploration with larger, randomized, controlled studies of biological medications in the treatment of acute GPP are needed in order to determine its efficacy and safety on a larger scale. ${ }^{47}$

\section{Pustular psoriasis of pregnancy History}

The pustular dermatitis, known today as pustular psoriasis of pregnancy, was first described in 1872 by Von Hebra using the term "impetigo herpetiformis". ${ }^{52}$ Later, clinical and histological studies of patients with impetigo herpetiformis led to the discovery of similarities between this entity and pustular psoriasis. However, the classification of this dermatitis as a disease distinct from pustular psoriasis is still debated, and in various studies, it continues to be discussed as impetigo herpetiformis. $^{10,53}$

\section{Epidemiology/presentation}

Pustular psoriasis of pregnancy is a rare autoimmune inflammatory dermatosis observed most commonly in the second half to third trimester of pregnancy. Some publications, however, report the occurrence as early as the first month of pregnancy. ${ }^{10,11,54,55}$ The true incidence of pustular psoriasis of pregnancy is unknown owing to the paucity of published cases. $^{54}$

Patients typically present with an eruption of numerous sterile pustules overlying annular or polycyclic erythematous patches, with lesions usually beginning within skin folds and spreading radially. ${ }^{53,56}$ The face, palms, and soles are largely spared. ${ }^{11}$ Constitutional symptoms may also be present, including fever, chills, malaise, nausea, diarrhea, dehydration, arthralgias, and even tachycardia and seizures. ${ }^{11,53}$ Common lab findings include leukocytosis with a neutrophilic predominance, anemia, increased erythrocyte sedimentation rate, as well as hypocalcemia, hypophosphatemia, hypoalbuminemia, and decreased vitamin D levels in some cases. ${ }^{5,11,53,57}$ In reports of more severe disease, hypocalcemia which led to tetany, delirium, and convulsions was observed. ${ }^{55}$

The presence of pustular psoriasis of pregnancy has been historically associated with poor neonatal outcomes including placental insufficiency, stillbirth, fetal abnormalities, and early neonatal death, with a correlation between severity and duration of the disease and poor neonatal prognosis. ${ }^{11,58,59}$ Maternal death has also been reported. ${ }^{52}$ Given this correlation, patients who present with severe or recalcitrant pustular psoriasis of pregnancy are often counseled regarding early induction of labor. ${ }^{10}$ Following delivery, many patients have dramatic and rapid resolution of their dermatologic disease. ${ }^{5,10,11}$ However, recurrence of disease in subsequent pregnancies is common. ${ }^{58,60}$

\section{Pathophysiology}

The pathophysiology of pustular psoriasis of pregnancy is even more elusive than in other forms of pustular psoriasis, which is likely due to the low incidence of the disease..$^{53,54}$ Female with pustular psoriasis of pregnancy seldom report a personal or family history of psoriasis; but in some cases, resolution of the acute pustular form of the disease results in lingering classic psoriatic lesions. ${ }^{55,57}$ As mentioned, an association between this disease in pregnant female and hypocalcemia or low serum vitamin D levels may be present, but these lab findings are not evident in all patients and there is no evidence to support causality of these abnormal lab values. ${ }^{55}$

Literature on the theoretical pathogenesis of pustular psoriasis of pregnancy typically discusses possible triggers associated with development of the disease. Potential triggers include increasing levels of progesterone during the last trimester of pregnancy, hypocalcemia, and lower levels of elafin, an epidermal skin-derived antileukoproteinase, which may all contribute to the production of epidermal pustules. ${ }^{61}$ Associations with hormonal contraception, increased stress levels, seasonal changes, concurrent bacterial infections, and certain medications have been described..$^{53}$ There have also been reports of the association between pustular psoriasis of pregnancy and hypothyroidism. ${ }^{62}$

Another important consideration in defining the theoretical pathogenesis of pustular psoriasis of pregnancy involves specific situations in which patients suffer from an acute eruption or worsening of GPP during pregnancy. Pregnancy has been noted as a precipitating factor for the new development or acute flare of GPP. ${ }^{12,16,25,63-65}$

\section{Treatment}

Patients should be assessed by their obstetrician for potential early induction of labor as the first and best therapeutic option for this disease. In terms of therapeutic options, systemic corticosteroids are widely accepted to be the most commonly used first-line treatment for pustular psoriasis of pregnancy (Table 2). ${ }^{54,66}$ Robinson et al ${ }^{18}$ developed a treatment algorithm for GPP in pregnancy, which included cyclosporine, infliximab, topical corticosteroids, and topical calcipotriene as the first-line treatment options, in addition to systemic prednisone. ${ }^{43,66-69}$ Case reports regarding the successful use of cyclosporine in this disease are present in the literature. ${ }^{11}$ An algorithm for second-line treatment options include PUVA 
Table 2 Treatment of pustular psoriasis of pregnancy

\begin{tabular}{|c|c|c|c|c|}
\hline Medication & Dosage & Route & Pregnancy category & Notes \\
\hline \multicolumn{5}{|l|}{ First line } \\
\hline Corticosteroids & $\begin{array}{l}\text { Prednisolone at } 15-30 \mathrm{mg} / \text { day with } \\
\text { maximum of } 60-80 \mathrm{mg} / \text { day }\end{array}$ & Oral & $\begin{array}{l}\text { C/D - use lowest dosage } \\
\text { possible }\end{array}$ & $\begin{array}{l}\text { More effective when used with } \\
\text { cyclosporine }\end{array}$ \\
\hline Cyclosporine & $2-3 \mathrm{mg} / \mathrm{kg} / \mathrm{day}$ & Oral & C & $\begin{array}{l}\text { Not associated with increased risk of } \\
\text { adverse effects during pregnancy at this } \\
\text { dose }\end{array}$ \\
\hline Infliximab & $5 \mathrm{mg} / \mathrm{kg}$ at week $\mathrm{I}, 2$, and 6 & IV & B & Rapid onset, effective for acute disease \\
\hline Corticosteroids & Standard dosing & Topical & $\begin{array}{l}\text { Unknown - use lowest } \\
\text { potency possible }\end{array}$ & \\
\hline Calcipotriene & $50 \mu g / g$ & Topical & C & \\
\hline \multicolumn{5}{|l|}{ Second line } \\
\hline PUVA & Standard dosing & Topical & C & Not for acute disease \\
\hline UVB & $\begin{array}{l}69 \mathrm{~mJ} / \mathrm{cm} \text { three times weekly increased } \\
\text { at } 10 \% \text { increments with each treatment } \\
\text { for sessions I-34 and by } 5 \% \text { increments } \\
\text { for treatments } 34-42\end{array}$ & Topical & Safe & $\begin{array}{l}\text { Often effective when resistant to topical } \\
\text { corticosteroids }\end{array}$ \\
\hline \multicolumn{5}{|c|}{ Alternative therapies } \\
\hline Retinoid + PUVA & $\begin{array}{l}\text { Isotretinoin } 40 \mathrm{mg} / \text { day and } \\
5 \text {-methoxypsoralen } 1.5 \mathrm{mg} / \mathrm{kg} \\
\text { body weight }\end{array}$ & Oral/topical & $x$ & Only after delivery of the infant \\
\hline Ustekinumab & Standard dosing & SC & B & $\begin{array}{l}\text { For severe, recalcitrant disease; lack of } \\
\text { fetal safety data (biologics are generally } \\
\text { considered category B) }\end{array}$ \\
\hline
\end{tabular}

Note: Induction of labor for delivery of the infant should be performed if possible.

Abbreviations: IV, intravenous; PUVA, psoralen plus ultraviolet-A; SC, subcutaneous; UVB, ultraviolet-B.

and ultraviolet-B (UVB) therapy following delivery. ${ }^{19,70,71}$ Related to this treatment regimen are published reports of successful use of retinoid photochemotherapy (involving isotretinoin and PUVA) after unsuccessful attempts with first-line therapies and following delivery of the fetus. ${ }^{57}$ In cases of severe, recalcitrant pustular psoriasis of pregnancy, use of ustekinumab has also been reported as a successful alternative, despite the lack of fetal safety data and the general categorization of biologics as pregnancy category B drugs. ${ }^{72}$

As mentioned, delivery of the fetus often results in rapid resolution of the dermatitis, which should be considered in cases of severe disease despite optimal medical management. . $^{5,10,11}$

\section{Infantile and juvenile pustular psoriasis}

While psoriasis is a common disease in children and adolescents, pustular psoriasis in patients younger than 18 years is exceedingly rare. ${ }^{73}$ There are only a few reports in the literature regarding pustular psoriasis in children, owing to its rarity. ${ }^{74}$ One report reviewing 12 cases of juvenile pustular psoriasis indicates a 2:1 male predominance. ${ }^{75}$ The average age of onset ranges from 6.6 to 7.6 years. ${ }^{75,76}$ The diagnosis is typically made based on clinical and histological features. ${ }^{75}$ Clinically, juvenile pustular psoriasis can present in a diffuse generalized pustular pattern similar to adult GPP, or more commonly, it can present in a circinate or annular pattern. ${ }^{77}$ The affected children often have systemic findings including fever, as well as lab abnormalities such as leukocytosis and elevated erythrocyte sedimentation rate. ${ }^{75}$

The etiology and pathogenesis of juvenile pustular psoriasis are unknown. ${ }^{75}$ The disease has been reported in several sibling or other familial associations, lending to the theory of at least a partial genetic component to the dermatosis. ${ }^{78}$ Juvenile pustular psoriasis, like other forms of psoriasis, is often associated with identifiable triggers such as infection, vaccination, and corticosteroid withdrawal. ${ }^{79}$

\section{Treatment}

The rarity of pustular psoriasis in children has also led to a lack of evidence-based treatment literature. ${ }^{74}$ The Medical Board of the National Psoriasis Foundation has published guidelines on the treatment of pustular psoriasis in children. First-line therapy for this disease is similar to that of pustular psoriasis in adults. Acitretin, cyclosporine, etanercept, or methotrexate can each be used safely as first-line therapeutic options in children with pustular psoriasis (Table 3). ${ }^{18}$ Second-line therapeutic options include adalimumab, infliximab, and UVB phototherapy. ${ }^{18}$ Juvenile pustular psoriasis 
Table 3 Treatment of infantile and juvenile pustular psoriasis

\begin{tabular}{|c|c|c|c|}
\hline Medication & Dosage & Route & Notes \\
\hline \multicolumn{4}{|l|}{ First line } \\
\hline Acitretin & $<\mathrm{lmg} / \mathrm{kg} / \mathrm{day}$ & Oral & $\begin{array}{l}\text { Severe or recalcitrant disease; consider the potential for skeletal } \\
\text { toxicity; relative contraindication in reproductive age girls (consider } \\
\text { isotretinoin instead) }\end{array}$ \\
\hline Acitretin + prednisone & Standard dosing & Oral & For acute disease \\
\hline Cyclosporine & $\mathrm{I}-3 \mathrm{mg} / \mathrm{kg} / \mathrm{day}$ for $2-4$ weeks & Oral & $\begin{array}{l}\text { Fewer long-term adverse effects than retinoids, corticosteroids, or } \\
\text { methotrexate }\end{array}$ \\
\hline Methotrexate & $0.2-0.4 \mathrm{mg} / \mathrm{kg} /$ week & Oral & Successful in children as young as 2 years of age \\
\hline Etanercept & $0.4 \mathrm{mg} / \mathrm{kg}$ twice weekly for 2 months & SC & $\begin{array}{l}\text { Limited data, but may have safety advantages as seen in plaque } \\
\text { psoriasis literature }\end{array}$ \\
\hline \multicolumn{4}{|l|}{ Second line } \\
\hline Adalimumab & $40 \mathrm{mg}$ every other week & SC & \\
\hline Infliximab & Standard dosing & IV & \\
\hline UVB & Standard dosing & Topical & $\begin{array}{l}\text { Effective as adjunctive therapy with systemic retinoids for maintenance } \\
\text { (but contraindicated in children }<12 \text { years old) }\end{array}$ \\
\hline
\end{tabular}

Abbreviations: IV, intravenous; SC, subcutaneous; UVB, ultraviolet-B.

has a characteristic tendency to recur frequently, and in some cases, it has been reported to recur on an annual basis. ${ }^{75,76}$

\section{Localized pustular psoriasis Palmoplantar pustular psoriasis History}

Palmoplantar pustular psoriasis (PPP), also known as palmoplantar pustulosis, is a form of localized pustular psoriasis on the palms and/or soles. This entity was first described in 1888 by Crocker with the name "dermatitis repens" ${ }^{80}$ The classification of palmoplantar pustulosis remains an area of debate. Several authors propose that PPP is a distinct entity, while others believe PPP is a variant of psoriasis. ${ }^{2,81}$

\section{Epidemiology/presentation}

Palmoplantar pustular psoriasis (PPP) presents clinically as sterile pustules with erythema, hyperkeratosis, and scaling on the palms and soles (Figure 2). ${ }^{82}$ The disease tends to predominate on the thenar, hypothenar, and central areas of the palms, as well as the corresponding areas of the soles, and it can extend proximally to the patient's wrists and heels..$^{81,83}$ The pustular lesions may expand and coalesce before resolving, commonly resulting in a brown discoloration upon resolution. ${ }^{81}$ PPP affects female more frequently than male. ${ }^{84} \mathrm{~A}$ study conducted in Japan comparing the clinical and epidemiological characteristics of PPP and palmoplantar psoriasis found a significant female predominance of $67 \% .^{83}$

\section{Pathophysiology}

Multiple precipitating factors have been found to predispose patients to the induction of palmoplantar psoriasis, including

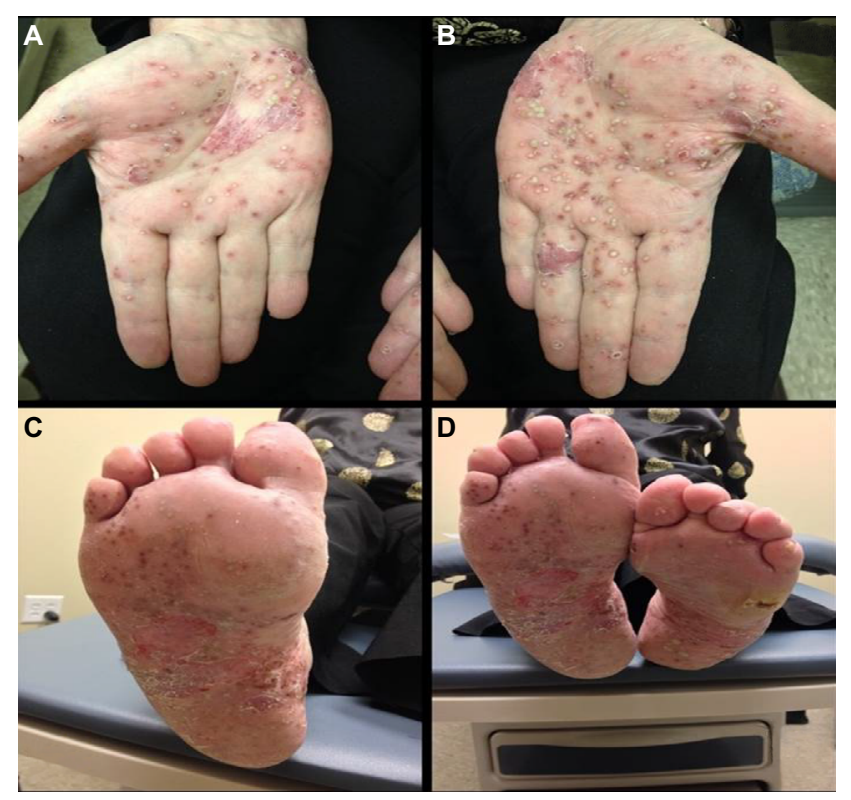

Figure 2 Palmoplantar pustular psoriasis.

Notes: (A, B) Multiple pustules studded on the palmar surface of the hands with a few areas of erythematous desquamative changes. (C, D) Innumerable pustules and small areas of hyperpigmentation in areas of prior pustules noted on the plantar feet with desquamation and mild erythema. Used with permission of Professor Alan Menter, Baylor University Medical Center.

smoking, metal sensitivities, infections, trauma, stress, and medications. ${ }^{7,82,85-88}$

Smoking is widely known as one of the most important precipitating factors for the development of PPP. Many studies have shown the impressive association between smoking and PPP, citing the prevalence to be between 33\% and 95\%. ${ }^{7,98,83}$ Smoking has been found to be related to increased levels of IL-17, propagating inflammation in patients with a predisposition for PPP. ${ }^{89,90}$ Smoking can also influence the expression of nicotinic acetylcholine receptors which 
can be found in the acrosyringium. Patients with PPP are thought to have an abnormal response to nicotine, resulting in inflammation with smoking. ${ }^{91}$ The role of smoking in the pathogenesis of PPP is further supported by the findings that cessation of smoking can lead to improvement or near resolution of PPP. ${ }^{85,86,92,93}$

Sensitivities to metals have also been cited as precipitating factors in PPP. ${ }^{90,94}$ The most common metal sensitivity described is to nickel and occurs in $3 \%$ of patients with PPP. ${ }^{83}$ Other metal allergies described include chrome and cobalt. ${ }^{85}$

Infections are another well-recognized precipitating factor for PPP. The most commonly cited infection resulting in an eruption or exacerbation of PPP is tonsillitis. ${ }^{12}$ According to Takahara, tonsillectomy in patients resulted in subjective improvement of the disease in $94 \%$ and objective improvement of the disease in $88 \%$ of patients with PPP. ${ }^{95}$ Other infections associated with PPP include dental infections such as dentoalveolar abscesses, periodontitis, and dental caries, as well as sinusitis. ${ }^{7,96}$ The theory that focal infections play a central role in the exacerbation of PPP is supported by evidence of improvement or near resolution of skin findings following resolution of the patient's infection. ${ }^{7,95,96}$

The Koebner phenomenon can also be associated with new lesions in PPP ${ }^{83,91,97}$ In PPP, mechanical stimulation is commonly caused by shoes, resulting in lesions on the soles of patients predisposed to the development of PPP. ${ }^{86}$

Stressful psychological conditions also impact the onset and worsening of PPP. ${ }^{87}$ Results from questionnaires provided to patients with PPP showed that $43 \%$ of patients with PPP exhibited behaviors consistent with anxiety, worry, and psychosomatic disorders, compared to only $19 \%$ of subjects in the control groups. ${ }^{87}$ Others have shown that up to $46 \%$ of patients report worsening of PPP during periods of stress. ${ }^{9}$

Furthermore, a seasonal influence has also been described for the onset of PPP with the onset and exacerbation worsened by humid and hot conditions. ${ }^{7,87,98}$

Perhaps the most frustrating precipitating factor noted for PPP is the association with anti-TNF- $\alpha$ inhibitors. ${ }^{99}$ The importance of TNF- $\alpha$-inhibitory therapy as a mainstay for treatment in chronic plaque psoriasis is well known. However, treatment of psoriasis with TNF- $\alpha$ inhibitors can cause a paradoxical flare of pustular psoriasis, especially of the palmoplantar morphology. ${ }^{88}$ This effect has been noted to be a class effect with most TNF- $\alpha$ blocking medications, rather than with specific agents. ${ }^{88}$ The mechanism behind the relationship between PPP and TNF- $\alpha$ inhibitor therapy remains to be elucidated.
In support of the theory that PPP is a clinical variant of psoriasis, authors have discussed the morphological, clinical, and histological similarities between PPP and psoriasis. ${ }^{83}$ Yamamoto $^{86}$ discussed the relationship between PPP and psoriasis with evidence of the eruption of plaque-like lesions on the trunk of individuals diagnosed with PPP. Brunasso et $\mathrm{al}^{83}$ supported the same relationship with a retrospective study comparing two groups of patients, one with PPP and the other with psoriasis, and found close similarities between the groups in age of onset, family history of psoriasis, duration of the disease, comorbidities, and smoking status. Eriksson et $\mathrm{al}^{9}$ discussed similarities regarding the histology of the two diseases, specifically regarding neutrophil dysfunction and specific serum studies including eosinophilic cationic protein elevations and other chemokinetic effects in PPP compared to psoriasis vulgaris.

Authors in support of the theory that PPP is a distinct entity from psoriasis vulgaris argue several different points. Many authors discuss the strong genetic evidence of differences between PPP and psoriasis, specifically, the absence of association with PSORS1 locus in PPP, which is common for psoriasis vulgaris, and the presence of IL-36RA mutations in some patients with PPP, which are lacking in patients with psoriasis vulgaris..$^{1,8,17,100,101}$ Other authors argue that the strong association between smoking and metal intolerance with PPP that is absent in psoriasis vulgaris warrants distinct classification of the disease. ${ }^{85}$ PPP is also associated with SAPHO syndrome (synovitis, acne, palmoplantar pustulosis, hyperostosis, and osteitis), a syndrome that does not have an association with psoriasis vulgaris. $^{92}$

The pathophysiology of PPP remains as obscure as its classification. It is widely accepted, however, that the eccrine sweat gland is significant to its pathogenesis. Specifically, the acrosyringium (the most intraepidermal portion of the eccrine sweat gland consisting of the terminal spiral duct) serves as the primary site of inflammation and pustule formation, as supported by evidence of specific chemicals unique to eccrine sweat glands found in the cells lining the vesicles of PPP patients. ${ }^{89,102}$ Furthermore, recent studies have begun to emphasize the importance of the innate immune system in the development of PPP. Langerhans cells can be found in increased numbers in both lesional and nonlesional skin of PPP patients, supporting an antigen-driven process for inflammation in the disease..$^{98}$ The inflammation is further driven by the proliferation of inflammatory cytokines such as IL-8 and IL-17. ${ }^{94} \mathrm{IL}-17 \mathrm{~A}$ is highly expressed in the palms 
and soles of patients with PPP in comparison to healthy subjects, ${ }^{89}$ while interestingly, IL-12 and IL-23 are not significantly expressed in these areas of patients with PPP. These findings imply a more central role for IL-17A in the inflammatory process for PPP compared to IL-12/IL-23, a difference which could have important implications for treatment. ${ }^{89}$

\section{Treatment}

Palmoplantar forms of psoriasis are notoriously recalcitrant to therapy. ${ }^{36}$ Uncertainties regarding the pathophysiology of palmoplantar disease lead to lack of a biogenetic understanding for the development of new pharmacological therapies. Like other pustular psoriasis forms, high-quality data regarding the treatment options and efficacies are lacking for PPP. First-line topical therapy involves corticosteroids under occlusion (Table 4). ${ }^{18}$ Adisen et $a l^{97}$ have described successful use of topical corticosteroids, especially under occlusive dressing, for the prevention of new pustule formation in PPP, as well. Second-line topical therapy includes calcipotriene, PUVA, photodynamic therapy, and tacrolimus. ${ }^{18}$ Topical treatment, however, uncommonly leads to remission of the disease, and progression to systemic treatment is often required. ${ }^{97}$ First-line systemic therapy for PPP includes acitretin. $^{18}$

Second-line systemic therapy involves the use of cyclosporine and biologic agents. The use of biologic agents in the treatment of PPP is becoming more pervasive, given the recalcitrant nature of the disease. The use of anti-TNF- $\alpha$ blocking agents, including adalimumab, etanercept, and infliximab, in PPP has been reported to be successful in case reports and small studies. ${ }^{82,103-105}$ Morales-Munera et $\mathrm{al}^{82}$ have described the successful use of ustekinumab in five patients with severe, refractory palmoplantar pustulosis, all of whom experienced positive results in 2-3 weeks after the first dose and complete resolution at 20 weeks after therapy. Cases of PPP successfully treated with efalizumab, an anti-leukocyte function-associated antigen-1 monoclonal antibody, have also been reported. ${ }^{88,106}$ However, efalizumab has since been removed from the market secondary to concerns regarding progressive multifocal leukoencephalopathy. ${ }^{36}$

Table 4 Treatment of palmoplantar pustular psoriasis

\begin{tabular}{|c|c|c|c|}
\hline Medication & Dosage & Route & Notes \\
\hline \multicolumn{4}{|l|}{ First line - local therapy } \\
\hline Corticosteroids under occlusion & Twice daily & Topical & Results are transient \\
\hline \multicolumn{4}{|l|}{ Second line - local therapy } \\
\hline Calcipotriene & Twice daily & Topical & For single nail psoriasis or to control relapse \\
\hline Tacrolimus & Twice daily & Topical & \\
\hline PUVA & Standard dosing & Topical & \\
\hline Photodynamic therapy & Standard dosing & Topical & $\begin{array}{l}308 \mathrm{~nm} \text { monochromic excimer; results not long lasting; } \\
\text { can be used in conjunction with aminolevulinic acid and } \\
\text { hematoporphyrin-containing ointment }\end{array}$ \\
\hline \multicolumn{4}{|l|}{ First line - systemic therapy } \\
\hline Acitretin & Standard dosing & Oral & Can be used in combination with second-line agents \\
\hline \multicolumn{4}{|l|}{ Second line - systemic therapy } \\
\hline Cyclosporine & $\mathrm{I}-2 \mathrm{mg} / \mathrm{kg} / \mathrm{day}$ & Oral & \\
\hline Adalimumab & Standard dosing & $\mathrm{SC}$ & \\
\hline Etanercept & Standard dosing & SC & \\
\hline Infliximab & Standard dosing & IV & $\begin{array}{l}\text { Especially effective for rapid improvement prior to switching } \\
\text { to another TNF antagonist such as etanercept or adalimumab }\end{array}$ \\
\hline Ustekinumab & Standard dosing & SC & \\
\hline \multicolumn{4}{|l|}{ Other potential therapies } \\
\hline $\begin{array}{l}\text { Anti-IL-I7A agents } \\
\text { - Secukinumab } \\
\text { - Ixekizumab }\end{array}$ & Standard dosing & & \\
\hline $\begin{array}{l}\text { Anti-IL-I agents } \\
\text { - Anakinra } \\
\text { - Canakinumab }\end{array}$ & & & \\
\hline PUVA & Standard dosing & Oral & \\
\hline Retinoid + PUVA & Standard dosing & Oral & \\
\hline
\end{tabular}

Abbreviations: IL, interleukin; IV, intravenous; PUVA, psoralen plus ultraviolet-A; SC, subcutaneous; TNF, tumor necrosis factor. 


\section{Acrodermatitis continua of Hallopeau History}

$\mathrm{ACH}$ is another localized form of pustular psoriasis which is historically described using a number of various aliases including acrodermatitis perstans, dermatitis repens, acropustulosis, and pustular acrodermatitis. ${ }^{107,108}$ The classification of $\mathrm{ACH}$ has also been controversial since it was first described, with some authors considering $\mathrm{ACH}$ a skin disorder distinct from GPP and others considering $\mathrm{ACH}$ to be a variant of the generalized pustular disease. ${ }^{6}$

\section{Epidemiology/presentation}

$\mathrm{ACH}$ is a chronic form of pustular psoriasis that characteristically involves the digits and most commonly, the fingertips and nails. ${ }^{6} \mathrm{ACH}$ often presents as sterile pustules on the most distal portions of the fingers and toes (Figure 3). ${ }^{107}$ It is often painful and extensive with characteristic proximal progression of the sterile pustules leading to onychodystrophy or anonychia. ${ }^{6,107}$ $\mathrm{ACH}$ can have a similar presentation to other pustular disorders of the hands and feet, especially palmoplantar pustulosis. Characteristics that can be utilized to distinguish the various etiologies include ACH's predisposition for the periungual areas as well as its ability to remain localized to a limited number of digits for many years. ${ }^{109,110} \mathrm{ACH}$ is most common in middle-aged female. ${ }^{111}$ Further epidemiologic studies have not been conducted owing to the rarity of disease, and as such, most data have been obtained from anecdotal reports. ${ }^{112}$

\section{Pathophysiology}

$\mathrm{ACH}$, like GPP, is also associated with precipitating factors. Those precipitating factors most closely associated with $\mathrm{ACH}$ include localized trauma to the distal portion of a digit and localized infections. ${ }^{1,111,113}$

As mentioned, the classification of $\mathrm{ACH}$ has long been debated with $\mathrm{ACH}$ possibly being a distinct disease or a variant of GPP. Support for the latter classification is provided both by case reports involving the transition of $\mathrm{ACH}$ to GPP and the presence of IL-36RA mutations in patients with $\mathrm{ACH}$, which is the same genetic mutation found in some patients with GPP. 6,114

\section{Treatment}

Treatment of $\mathrm{ACH}$ is primarily based on data from case reports. ACH is notoriously recalcitrant to many therapies. ${ }^{107}$ Treatments that have been attempted historically included antibiotics and tar. ${ }^{107}$ Current first-line topical treatment for $\mathrm{ACH}$ is corticosteroid use under occlusion (Table 5). Secondline topical treatments include calcipotriol, tacrolimus, and fluorouracil, or a combination of these medications. ${ }^{107}$ However, these medications often do not prevent the occurrence of relapses and progression to systemic treatment is often necessary. ${ }^{107}$ First-line systemic therapies involve the use of cyclosporine and acitretin, and biologic agents. Biologic agents have more recently become the mainstay of treatment in recalcitrant forms of $\mathrm{ACH}$. Ustekinumab was successfully used to treat a patient with $\mathrm{ACH} .{ }^{115} \mathrm{TNF}-\alpha$ inhibitors have proven to be the most efficacious and include the use of infliximab, adalimumab, and etanercept, especially in recalcitrant cases of ACH. ${ }^{107,116}$ Efalizumab has also historically been used successfully in the treatment of $\mathrm{ACH}$, but efalizumab, as mentioned, is no longer commercially available. ${ }^{36,117}$ Second-line systemic therapies include systemic corticosteroids, methotrexate, retinoids, PUVA, and narrow- and broad-band UVB. ${ }^{107}$

Evidence-based treatment strategies for $\mathrm{ACH}$ are lacking due to the difficulty in diagnosis of $\mathrm{ACH}$ and the lack of knowledge regarding the pathophysiology and etiology of the disease. Future management of $\mathrm{ACH}$ requires larger controlled studies and further studies on the pathophysiology of the disease, which will likely guide the development of new and effective medications for treatment.

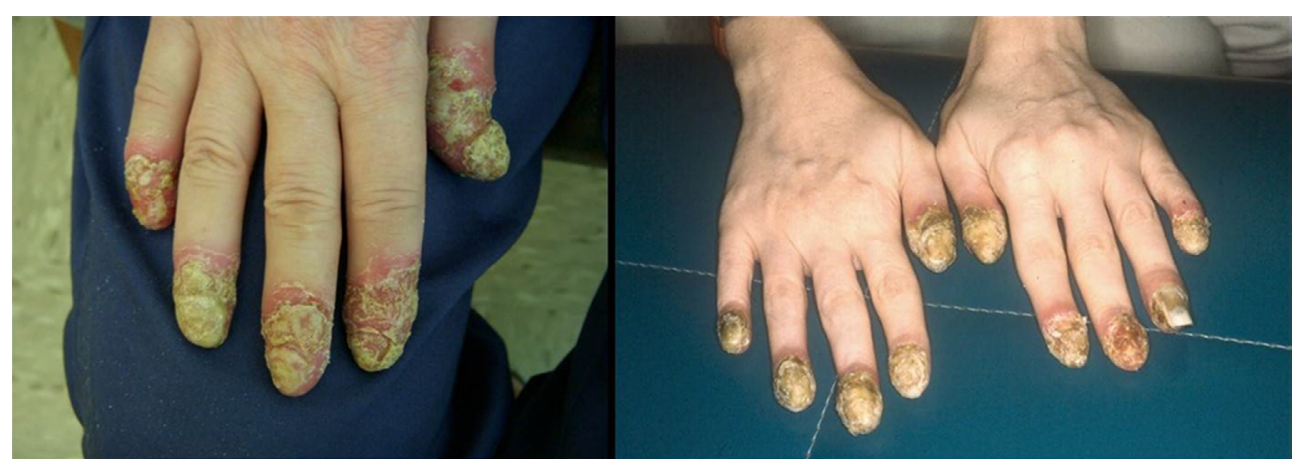

Figure 3 Acrodermatitis continua of Hallopeau.

Note: Erythematous plaques, hyperkeratosis, and pustules confined to the distal tips of all digits with nail involvement. Used with permission of Professor Alan Menter, Baylor University Medical Center. 
Table 5 Treatment of acrodermatitis continua of hallopeau

\begin{tabular}{|c|c|c|c|}
\hline Medication & Dosage & Route & Notes \\
\hline \multicolumn{4}{|l|}{ First line - topical } \\
\hline Corticosteroids under occlusion & Standard dosing & Topical & \\
\hline \multicolumn{4}{|l|}{ Second line - topical } \\
\hline Calcipotriol & $50 \mu \mathrm{g} / \mathrm{g}$ ointment BID & Topical & \\
\hline Fluorouracil & $5 \%$ cream & Topical & Recurrence after stopping \\
\hline Tacrolimus & $\begin{array}{l}0.03 \%-0.1 \% \text { cream/ointment applied BID with one } \\
\text { application being under occlusion overnight for I-2 weeks, } \\
\text { then once daily under occlusion for I-2 weeks; } \\
\text { maintenance therapy of once weekly }\end{array}$ & Topical & Minor recurrence \\
\hline \multicolumn{4}{|l|}{ First line - systemic } \\
\hline Cyclosporine & $3-5 \mathrm{mg} / \mathrm{kg} /$ day & Oral & \\
\hline Acitretin & $45 \mathrm{mg} /$ day, $35-40 \mathrm{mg} /$ day, $35 \mathrm{mg} /$ day & Oral & Dosing based on case reports \\
\hline Adalimumab & Standard dosing & SC & \\
\hline Etanercept & Standard dosing & SC & \\
\hline Infliximab & Standard dosing & IV & \\
\hline Ustekinumab & Standard dosing & SC & \\
\hline \multicolumn{4}{|l|}{ Second line - systemic } \\
\hline \multirow[t]{2}{*}{ Corticosteroids } & Prednisolone 75 mg daily & Oral & \\
\hline & $\begin{array}{l}\text { Single dose of triamcinolone acetonide } 60 \mathrm{mg} \text {, then repeat } \\
\text { dose } 1-2 \text { weeks later }\end{array}$ & IM & \\
\hline Methotrexate & I5-25 mg/weekly & Oral & \\
\hline Etretinate & $\begin{array}{l}20 \mathrm{mg} / \text { day gradually increased to } 70 \mathrm{mg} / \text { day over } 5 \text { months; } \\
25 \mathrm{mg} \text { BID for I month then decreased to } 35 \mathrm{mg}\end{array}$ & Oral & Dosing based on case reports \\
\hline PUVA-bath & 24 treatment sessions & Topical & Dosing based on case reports \\
\hline Broadband UVB and thalidomide & BB-UVB + thalidomide $50 \mathrm{mg} /$ day for 2 months & Topical & Dosing based on case reports \\
\hline 8-MOP + narrow band UVB & $\begin{array}{l}0.1 \% \text { 8-MOP applied following NB-UVB phototherapy } \\
\text { twice weekly }\end{array}$ & Topical & \\
\hline Narrow band UVB & $\begin{array}{l}\text { Targeted NB-UVB twice weekly starting at } 80 \% \text { minimum } \\
\text { erythema dose and increasing by } 20 \% \text { each session }\end{array}$ & Topical & $\begin{array}{l}\text { Dosing and results based on } \\
\text { case reports }\end{array}$ \\
\hline \multicolumn{4}{|l|}{ Other reported combinations } \\
\hline Etanercept + acitretin & $\begin{array}{l}\text { Etanercept } 25 \mathrm{mg} \text { twice weekly + acitretin } 75 \mathrm{mg} / \text { day, then } \\
\text { increasing etanercept to } 50 \mathrm{mg} \text { twice weekly }\end{array}$ & & \\
\hline Etanercept + methotrexate & $50 \mathrm{mg}$ twice weekly + methotrexate $10 \mathrm{mg}$ weekly & & \\
\hline Acitretin + prednisone + infliximab & $\begin{array}{l}\text { Acitretin } 0.25 \mathrm{mg} / \mathrm{kg} / \text { day orally + prednisone } 10 \mathrm{mg} / \text { day } \\
\text { orally + infliximab } 5 \mathrm{mg} / \mathrm{kg} \text { IV for } 2 \text { weeks, then infliximab } \\
\text { only } 5 \mathrm{mg} / \mathrm{kg} \text { IV every } 8 \text { weeks for maintenance }\end{array}$ & & \\
\hline
\end{tabular}

Abbreviations: BID, twice daily; IM, intramuscular; IV, intravenous; PUVA, psoralen plus ultraviolet-A; SC, subcutaneous; UVB, ultraviolet-B; 8-MOP, 8-methoxypsoralen; NB-UVB, narrowband ultraviolet B.

\section{Conclusion}

Psoriasis vulgaris is a chronic inflammatory disease that classically affects skin and joints and is associated with numerous comorbidities. There are several clinical subtypes of psoriasis including the uncommon pustular variants, which include acute GPP, pustular psoriasis of pregnancy, infantile and juvenile pustular psoriasis, $\mathrm{ACH}$, and PPP. These variants have similar histopathologic characteristics. However, the immunopathogenesis of each entity remains to be fully elucidated. As such, numerous therapies have shown variable results and most entities remain difficult to treat. In general, topical therapy should be used with lesssevere, more localized forms of the disease. There should be a low threshold to initiate systemic therapies, as most pustular forms of psoriasis are recalcitrant to topical and multiple systemic therapies. Combinations of systemic and topical therapies are encouraged. With increasing knowledge of the pathogenesis of these variants of pustular psoriasis, the development and use of biologic and other immunomodulatory therapies holds promise for the future of successfully treating pustular variants of psoriasis - including the therapies targeting IL-1, IL-17, the p19 unit of IL-23, and potentially IL-36.

\section{Acknowledgment}

We would like to thank Professor Alan Menter for providing the clinical images for the figures presented and for his continued mentorship. 


\section{Disclosure}

Dr Bobbak Mansouri has sat on an advisory board and received an honorarium from Celgene. All other authors have no conflicts of interest in this work.

\section{References}

1. Naldi L, Gambini D. The clinical spectrum of psoriasis. Clin Dermatol. 2007;25(6):510-518.

2. Griffiths CE, Christophers E, Barker JN, et al. A classification of psoriasis vulgaris according to phenotype. Br J Dermatol. 2007; 156(2):258-262.

3. Griffiths CEM, Camp RDR, Barker JNWN. Psoriasis. Rook's Textbook of Dermatology. Blackwell Publishing, Inc; 2008:1731-1800.

4. Raychaudhuri SK, Maverakis E, Raychaudhuri SP. Diagnosis and classification of psoriasis. Autoimmun Rev. 2014;13(4-5):490-495.

5. Oosterling RJ, Nobrega RE, Du Boeuff JA, Van Der Meer JB. Impetigo herpetiformis or generalized pustular psoriasis? Arch Dermatol. 1978;114(10):1527-1529.

6. Abbas O, Itani S, Ghosn S, et al. Acrodermatitis continua of Hallopeau is a clinical phenotype of DITRA: evidence that it is a variant of pustular psoriasis. Dermatol. 2013;226(1):28-31.

7. Akiyama T, Seishima M, Watanabe H, Nakatani A, Mori S, Kitajima Y. The relationships of onset and exacerbation of pustulosis palmaris et plantaris to smoking and focal infections. $J$ Dermatol. 1995;22(12):930-934.

8. Asumalahti K, Ameen M, Suomela S, et al. Genetic analysis of PSORS1 distinguishes guttate psoriasis and palmoplantar pustulosis. J Invest Dermatol. 2003;120(4):627-632.

9. Eriksson MO, Hagforsen E, Lundin IP, Michaelsson G. Palmoplantar pustulosis: a clinical and immunohistological study. Br J Dermatol. 1998;138(3):390-398.

10. Lotem M, Katzenelson V, Rotem A, Hod M, Sandbank M. Impetigo herpetiformis: a variant of pustular psoriasis or a separate entity? $J$ Am Acad Dermatol. 1989;20(2 Pt 2):338-341.

11. Bangale-Daflapurkar S, Danve A. Pustular psoriasis of pregnancy successfully treated with cyclosporine. Am J Ther. Epub 2015 Sep 10.

12. Iizuka H, Takahashi H, Ishida-Yamamoto A. Pathophysiology of generalized pustular psoriasis. Arch Dermatolog Res. 2003;295 Suppl 1:S55-S59.

13. Kardaun SH, Kuiper H, Fidler V, Jonkman MF. The histopathological spectrum of acute generalized exanthematous pustulosis (AGEP) and its differentiation from generalized pustular psoriasis. J Cutan Pathol. 2010;37(12):1220-1229.

14. Varman KM, Namias N, Schulman CI, Pizano LR. Acute generalized pustular psoriasis, von Zumbusch type, treated in the burn unit. a review of clinical features and new therapeutics. Burns. 2014; 40(4):e35-e39.

15. Choon SE, Lai NM, Mohammad NA, Nanu NM, Tey KE, Chew SF. Clinical profile, morbidity, and outcome of adult-onset generalized pustular psoriasis: analysis of 102 cases seen in a tertiary hospital in Johor, Malaysia. Int J Dermatol. 2014;53(6):676-684.

16. Borges-Costa Jo, Silva R, Goñ̃ falves L, Filipe P, Soares de Almeida LÂ, Marques Gomes M. Clinical and laboratory features in acute generalized pustular psoriasis: a retrospective study of 34 patients. Am J Clin Dermatol. 2011;12(4):271-276.

17. Setta-Kaffetzi N, Navarini AA, Patel VM, et al. Rare pathogenic variants in IL36RN underlie a spectrum of psoriasis-associated pustular phenotypes. J Invest Dermatol. 2013;133(5):1366-1369.

18. Robinson A, Van Voorhees AS, Hsu S, Korman NJ, Lebwohl MG, Bebo BF Jr, Kalb RE. Treatment of pustular psoriasis: from the Medical Board of the National Psoriasis Foundation. J Am Acad Dermatol. 2012;67(2):279-288.

19. Viguier M, Allez M, Zagdanski AM, et al. High frequency of cholestasis in generalized pustular psoriasis: evidence for neutrophilic involvement of the biliary tract. Hepatology. 2004;40(2): $452-458$.
20. Zelickson BD, Muller SA. Generalized pustular psoriasis. a review of 63 cases. Arch Dermatol. 1991;127(9):1339-1345.

21. Augey F, Renaudier P, Nicolas JF. Generalized pustular psoriasis (Zumbusch): a French epidemiological survey. Eur J Dermatol. 2006;16(6):669-673.

22. Ozawa A, Ohkido M, Haruki Y, et al. Treatments of generalized pustular psoriasis: a multicenter study in Japan. J Dermatol. 1999; 26(3):141-149.

23. Goiriz R, Dauden E, Perez-Gala S, Guhl G, Garcia-Diez A. Flare and change of psoriasis morphology during the course of treatment with tumour necrosis factor blockers. Clin Exp Dermatol. 2007;32(2):176-179.

24. Brenner M, Molin S, Ruebsam K, Weisenseel P, Ruzicka T, Prinz JC. Generalized pustular psoriasis induced by systemic glucocorticosteroids: four cases and recommendations for treatment. Br J Dermatol. 2009;161(4):964-966.

25. Wenk KS, Claros JM, Ehrlich A. Flare of pustular psoriasis after initiating ustekinumab therapy. J Dermatolog Treat. 2012;23(3):212-214.

26. Gregoriou S, Kazakos C, Christofidou E, Kontochristopoulos G, Vakis G, Rigopoulos D. Pustular psoriasis development after initial ustekinumab administration in chronic plaque psoriasis. Eur J Dermatol. 2011;21(1):104-105.

27. Ozturk G, Turk BG, Karaca N, et al. Generalized pustular eruptions due to terbinafine. Cutan Ocul Toxicol. 2012;31(1):81-84.

28. Marrakchi S, Guigue P, Renshaw BR, et al. Interleukin-36-receptor antagonist deficiency and generalized pustular psoriasis. $N$ Engl J Med. 2011;365(7):620-628.

29. Mahil SK, Capon F, Barker JN. Genetics of psoriasis. Dermatolog Clin. 2015;33(1):1-11.

30. Dietrich D, Gabay C. Inflammation: IL-36 has proinflammatory effects in skin but not in joints. Nat Rev Rheumatol. 2014;10(11):639-640.

31. Hussain S, Berki DM, Choon SE, et al. IL36RN mutations define a severe autoinflammatory phenotype of generalized pustular psoriasis. J Allergy Clin Immunol. 2015;135(4):1067-1070.e1069.

32. Onoufriadis A, Simpson Michael A, Pink Andrew E, et al. Mutations in IL36RN/IL1F5 are associated with the severe episodic inflammatory skin disease known as generalized pustular psoriasis. Am J Hum Genet. 2011;89(3):432-437.

33. Capon F. IL36RN mutations in generalized pustular psoriasis: just the tip of the iceberg? J Invest Dermatol. 2013;133(11):2503-2504.

34. Lowes MA, Suarez-Farinas M, Krueger JG. Immunology of psoriasis. Ann Rev Immunol. 2014;32:227-255.

35. Aksentijevich I, Masters SL, Ferguson PJ, et al. An autoinflammatory disease with deficiency of the interleukin-1-receptor antagonist. NEngl J Med. 2009;360(23):2426-2437.

36. Mansouri B, Patel M, Menter A. Biological therapies for psoriasis. Exp Opin Biol Ther. 2013;13(12):1715-1730.

37. Dauden E, Santiago-et-Sanchez-Mateos D, Sotomayor-Lopez E, Garcia-DiezA. Ustekinumab: effective in a patient with severe recalcitrant generalized pustular psoriasis. Br J Dermatol. 2010;163(6):1346-1347.

38. Levin EC, Debbaneh M, Koo J, Liao W. Biologic therapy in erythrodermic and pustular psoriasis. J Drugs Dermatol. 2014;13(3):342-354.

39. Torii H, Nakagawa H. Long-term study of infliximab in Japanese patients with plaque psoriasis, psoriatic arthritis, pustular psoriasis and psoriatic erythroderma. J Dermatol. 2011;38(4):321-334.

40. Jordan J, Bieber T, Wilsmann-Theis D. Adalimumab: safe and successful in severe pustular psoriasis. J Eur Acad Dermatol Venereol. 2009;23(5):592-593.

41. Honigsmann H, Gschnait F, Konrad K, Wolff K. Photochemotherapy for pustular psoriasis (von Zumbusch). Br J Dermatol. 1977;97(2): 119-126.

42. Esposito M, Mazzotta A, Casciello C, Chimenti S. Etanercept at different dosages in the treatment of generalized pustular psoriasis: a case series. Dermatology. 2008;216(4):355-360.

43. Umezawa Y, Ozawa A, Kawasima T, et al. Therapeutic guidelines for the treatment of generalized pustular psoriasis (GPP) based on a proposed classification of disease severity. Arch Dermatol Res. 2003;295(Suppl 1):S43-S54. 
44. Nagao K, Ishiko A, Yokoyama T, Tanikawa A, Amagai M. A case of generalized pustular psoriasis treated with topical tacrolimus. Arch Dermatol. 2003;139(9):1219.

45. Rodriguez Garcia F, Fagundo Gonzalez E, Cabrera-Paz R, et al. Generalized pustular psoriasis successfully treated with topical tacrolimus. Br J Dermatol. 2005;152(3):587-588.

46. Viguier M, Guigue P, Pages C, Smahi A, Bachelez H. Successful treatment of generalized pustular psoriasis with the interleukin-1-receptor antagonist Anakinra: lack of correlation with IL1RN mutations. Ann Int Med. 2010;153(1):66-67.

47. Huffmeier U, Watzold M, Mohr J, Schon MP, Mossner R. Successful therapy with anakinra in a patient with generalized pustular psoriasis carrying IL36RN mutations. Br J Dermatol. 2014;170(1):202-204.

48. Mansouri B, Richards L, Menter A. Treatment of two patients with generalized pustular psoriasis with the interleukin-1beta inhibitor gevokizumab. Br J Dermatol. 2015;173(1):239-241.

49. Bohner A, Roenneberg S, Eyerich K, Eberlein B, Biedermann T. Acute generalized pustular psoriasis treated with the IL-17A antibody secukinumab. JAMA Dermatol. 2016;152(4):482-484.

50. Furusawa K, Hasegawa T, Ikeda S. Immunosuppressant and infliximabresistant generalized pustular psoriasis successfully treated with granulocyte and monocyte adsorption apheresis. Ther Apher Dial. 2012;16(4):379-380.

51. Shukuya R, Hasegawa T, Niwa Y, Okuma K, Ikeda S. Granulocyte and monocyte adsorption apheresis for generalized pustular psoriasis. $J$ Dermatol. 2011;38(12):1130-1134.

52. Hebra FV. Ueber einzelne, wahrend der schwangerschaft am wochenbette und bei urinalkrankheiten der frauzen zu beobachtende hautkrankheiten. Vol 22: Wein Med Wochenschr; 1872.

53. Kondo RN, Araujo FM, Pereira AM, Lopes VC, Martins LM. Pustular psoriasis of pregnancy (impetigo herpetiformis)--case report. An Bras Dermatol. 2013;88(6 Suppl 1):186-189.

54. Roth MM. Pregnancy dermatoses: diagnosis, management, and controversies. Am J Clin Dermatol. 2011;12(1):25-41.

55. Kroumpouzos G, Cohen LM. Dermatoses of pregnancy. J Am Acad Dermatol. 2001;45(1):1-19; quiz 19-22.

56. Green MG, Bragg J, Rosenman KS, Pomeranz MK. Pustular psoriasis of pregnancy in a patient whose dermatosis showed features of acute generalized exanthematous pustulosis. Int $J$ Dermatol. 2009;48(3):299-303.

57. Breier-Maly J, Ortel B, Breier F, Schmidt JB, Honigsmann H. Generalized pustular psoriasis of pregnancy (impetigo herpetiformis). Dermatology. 1999;198(1):61-64.

58. Oumeish OY, Farraj SE, Bataineh AS. Some aspects of impetigo herpetiformis. Arch Dermatol. 1982;118(2):103-105.

59. Beveridge GW, Harkness RA, Livingstone JR. Impetigo herpetiformis in two successive pregnancies. Br J Dermatol. 1966;78(2):106-112.

60. Gligora M, Kolacio Z. Hormonal treatment of impetigo herpetiformis. Br J Dermatol. 1982;107(2):253.

61. Kuijpers AL, Schalkwijk J, Rulo HF, Peperkamp JJ, van de Kerkhof PC, de Jong EM. Extremely low levels of epidermal skin-derived antileucoproteinase/elafin in a patient with impetigo herpetiformis. Br J Dermatol. 1997;137(1):123-129.

62. Katsambas A, Stavropoulos PG, Katsiboulas V, Kostakis P, Panayiotopoulos A, Christofidou E, Petridis A. Impetigo herpetiformis during the puerperium. Dermatology. 1999;198(4):400-402.

63. Korber A, Mossner R, Renner R, et al. Mutations in IL36RN in patients with generalized pustular psoriasis. J Invest Dermatol. 2013;133(11):2634-2637.

64. Li X, Chen M, Fu X, et al. Mutation analysis of the IL36RN gene in Chinese patients with generalized pustular psoriasis with/without psoriasis vulgaris. J Dermatol Sci. 2014;76(2):132-138.

65. Chang SE, Kim HH, Choi JH, Sung KJ, Moon KC, Koh JK. Impetigo herpetiformis followed by generalized pustular psoriasis: more evidence of same disease entity. Int J Dermatol. 2003;42(9):754-755.

66. Edmonds EV, Morris SD, Short K, Bewley SJ, Eady RA. Pustular psoriasis of pregnancy treated with ciclosporin and high-dose prednisolone. Clin Exp Dermatol. 2005;30(6):709-710.
67. Finch TM, Tan CY. Pustular psoriasis exacerbated by pregnancy and controlled by cyclosporin A. Br J Dermatol. 2000;142(3):582-584.

68. Adachi A, Komine M, Hirano T, Tsuda H, Karakawa M, Murata S, Ohtsuki M. Case of generalized pustular psoriasis exacerbated during pregnancy, successfully treated with infliximab. J Dermatol. Epub 2016 Apr 30.

69. Sheth N, Greenblatt DT, Acland K, Barker J, Teixeira F. Generalized pustular psoriasis of pregnancy treated with infliximab. Clin Exp Dermatol. 2009;34(4):521-522.

70. Lohrisch I, Heilmann S, Haustein UF. [Impetigo herpetiformis and PUVA-treatment (author's trans1)]. Dermatol Monatschr. 1979;165(9):648-652.

71. Vun YY, Jones B, Al-Mudhaffer M, Egan C. Generalized pustular psoriasis of pregnancy treated with narrowband UVB and topical steroids. J Am Acad Dermatol. 2006;54(2 Supp1):S28-S30.

72. Andrulonis R, Ferris LK. Treatment of severe psoriasis with ustekinumab during pregnancy. J Drugs Dermatol. 2012;11(10):1240.

73. Farber EM, Nall L. Childhood psoriasis. Cutis. 1999;64(5):309-314.

74. Fialova J, Vojackova N, Vanousova D, Hercogova J. Juvenile generalized pustular psoriasis treated with etanercept. Dermatol Ther. 2014;27(2):105-108

75. Xiao T, Li B, He CD, Chen HD. Juvenile generalized pustular psoriasis. $J$ Dermatol. 2007;34(8):573-576.

76. Zaraa I, Fazaa B, Zeglaoui F, et al. [Pustular psoriasis in childhood in 15 cases]. Tunis Med. 2004;82(7):679-683.

77. Wollina U, Funfstuck V. Juvenile generalized circinate pustular psoriasis treated with oral cyclosporin A. Eur J Dermatol. 2001;11(2):117-119.

78. Hubler WR Jr. Familial juvenile generalized pustular psoriasis. Arch Dermatol. 1984;120(9):1174-1178.

79. Karamfilov T, Wollina U. Juvenile generalized pustular psoriasis. Acta Derm Venereol. 1998;78(3):220.

80. Crocker HR. Diseases of the Skin. London: H.K. Lewis; 1888.

81. Farley E, Masrour S, McKey J, Menter A. Palmoplantar psoriasis: a phenotypical and clinical review with introduction of a new qualityof-life assessment tool. J Am Acad Dermatol. 2009;60(6):1024-1031.

82. Morales-Munera C, Vilarrasa E, Puig L. Efficacy of ustekinumab in refractory palmoplantar pustular psoriasis. $\mathrm{Br} J$ Dermatol. 2013;168(4):820-824.

83. Brunasso AM, Puntoni M, Aberer W, Delfino C, Fancelli L, Massone C. Clinical and epidemiological comparison of patients affected by palmoplantar plaque psoriasis and palmoplantar pustulosis: a case series study. Br J Dermatol. 2013;168(6):1243-1251.

84. Hagforsen E, Awder M, Lefvert AK, Nordlind K, Michaelsson G. Palmoplantar pustulosis: an autoimmune disease precipitated by smoking? Acta Derm Venereol. 2002;82(5):341-346.

85. Ammoury A, El Sayed F, Dhaybi R, Bazex J. Palmoplantar pustulosis should not be considered as a variant of psoriasis. J Eur Acad Dermatol Venereol. 2008;22(3):392-393.

86. Yamamoto T. Extra-palmoplantar lesions associated with palmoplantar pustulosis. J Eur Acad Dermatol Venereol. 2009;23(11):1227-1232.

87. Saez-Rodriguez M, Noda-Cabrera A, Alvarez-Tejera S, et al. The role of psychological factors in palmoplantar pustulosis. J Eur Acad Dermatol Venereol. 2002;16(4):325-327.

88. Brunasso AM, Laimer M, Massone C. Paradoxical reactions to targeted biological treatments: a way to treat and trigger? Acta Derm Venereol. 2010;90(2):183-185.

89. Bissonnette R, Nigen S, Langley RG, Lynde CW, Tan J, FuentesDuculan J, Krueger JG. Increased expression of IL-17A and limited involvement of IL-23 in patients with palmo-plantar (PP) pustular psoriasis or PP pustulosis; results from a randomised controlled trial. J Eur Acad Dermatol Venereol. 2014;28(10):1298-1305.

90. Murakami M, Hagforsen E, Morhenn V, Ishida-Yamamoto A, Iizuka H. Patients with palmoplantar pustulosis have increased IL-17 and IL-22 levels both in the lesion and serum. Exp Dermatol. 2011;20(10):845-847.

91. Hagforsen E, Edvinsson M, Nordlind K, Michaelsson G. Expression of nicotinic receptors in the skin of patients with palmoplantar pustulosis. Br J Dermatol. 2002;146(3):383-391. 
92. de Waal AC, van de Kerkhof PC. Pustulosis palmoplantaris is a disease distinct from psoriasis. J Dermatol Treat. 2011;22(2):102-105.

93. Michaelsson G, Gustafsson K, Hagforsen E. The psoriasis variant palmoplantar pustulosis can be improved after cessation of smoking. J Am Acad Dermatol. 2006;54(4):737-738.

94. Kim DY, Kim JY, Kim TG, et al. A comparison of inflammatory mediator expression between palmoplantar pustulosis and pompholyx. J Eur Acad Dermatol Venereol. 2013;27(12):1559-1565.

95. Takahara M. Clinical outcome of tonsillectomy for palmoplantar pustulosis and etiological relationship between palmoplantar pustulosis and tonsils. Adv Otorhinolaryngol. 2011;72:86-88.

96. Kikuchi N, Yamamoto T. Dental infection as a triggering factor in palmoplantar pustulosis. Acta Derm Venereol. 2013;93(6):721-722.

97. Adisen E, Tekin O, Gulekon A, Gurer MA. A retrospective analysis of treatment responses of palmoplantar psoriasis in 114 patients. $J$ Eur Acad Dermatol Venereol. 2009;23(7):814-819.

98. Hagforsen E, Hedstrand H, Nyberg F, Michaelsson G. Novel findings of langerhans cells and interleukin-17 expression in relation to the acrosyringium and pustule in palmoplantar pustulosis. Br J Dermatol. 2010;163(3):572-579.

99. Shmidt E, Wetter DA, Ferguson SB, Pittelkow MR. Psoriasis and palmoplantar pustulosis associated with tumor necrosis factor-alpha inhibitors: the Mayo Clinic experience, 1998 to 2010. J Am Acad Dermatol. 2012;67(5):e179-e185.

100. Sugiura K, Takemoto A, Yamaguchi M, et al. The majority of generalized pustular psoriasis without psoriasis vulgaris is caused by deficiency of interleukin-36 receptor antagonist. $J$ Invest Dermatol. 2013;133(11):2514-2521.

101. Renert-Yuval Y, Horev L, Babay S, Tams S, Ramot Y, Zlotogorski A, Molho-Pessach V. IL36RN mutation causing generalized pustular psoriasis in a Palestinian patient. Int J Dermatol. 2014;53(7): 866-868.

102. Murakami M, Ohtake T, Horibe Y, Ishida-Yamamoto A, Morhenn VB, Gallo RL, Iizuka H. Acrosyringium is the main site of the vesicle/ pustule formation in palmoplantar pustulosis. $J$ Invest Dermatol. 2010;130(8):2010-2016.

103. Yawalkar N, Hunger RE. Successful treatment of recalcitrant palmoplantar pustular psoriasis with sequential use of infliximab and adalimumab. Dermatology. 2009;218(1):79-83.
104. Kasche A, Pfab F, Hein R, Athanasiadis GI, Ollert M, Ring J, Eberlein-König B. Severe psoriasis pustulosa palmaris et plantaris (Barber-Konigsbeck) treated successfully with soluble tumour necrosis factor receptor fusion protein (etanercept). $J$ Eur Acad Dermatol Venereol. 2007;21(2):255-257.

105. Ahmad K, Rogers S. Three years' experience with infliximab in recalcitrant psoriasis. Clin Exp Dermatol. 2006;31(5):630-633.

106. Colsman A, Carrascosa JM, Ferrandiz C, Simon JC. Successful treatment of recalcitrant palmoplantar psoriasis with efalizumab. $J$ Eur Acad Dermatol Venereol. 2008;22(9):1131-1134.

107. Sehgal VN, Verma P, Sharma S, Srivastava G, Aggarwal AK, Rasool F, Chatterjee K. Acrodermatitis continua of Hallopeau: evolution of treatment options. Int J Dermatol. 2011;50(10):1195-1211.

108. Cymerman RM, Cohen DE. Treatment of acrodermatitis continua of hallopeau with ustekinumab as monotherapy. JAMA Dermatol. 2016;152(3):346-348.

109. William D. James TB, Dirk Elston. Andrews' Diseases of the Skin Clinical Dermatology. 10th ed. Canada: Saunders Elsevier; 2006.

110. Roenigk H. Psoriasis. 3rd ed. New York: Marcel Dekker Inc; 1998.

111. Yerushalmi J, Grunwald MH, Hallel-Halevy D, Avinoach I, Halevy S. Chronic pustular eruption of the thumbs. Diagnosis: acrodermatitis continua of Hallopeau (ACH). Arch Dermatol. 2000;136(7):925-930.

112. Puig L, Barco D, Vilarrasa E, Alomar A. Treatment of acrodermatitis continua of Hallopeau with TNF-blocking agents: case report and review. Dermatology. 2010;220(2):154-158.

113. Rosenberg BE, Strober BE. Acrodermatitis continua. Dermatol Online J. 2004;10(3):9.

114. Ranugha PS, Kumari R, Thappa DM. Acrodermatitis continua of hallopeau evolving into generalised pustular psoriasis. Indian J Dermatol. 2013;58(2):161.

115. Abbas M, Holfeld K, Desjardins D, Zimmer J. Pustular psoriasis complicated with acute generalized exanthematous pustulosis. J Dermatol Case Rep. 2014;8(2):42-45.

116. Di Costanzo L, Napolitano M, Patruno C, Cantelli M, Balato N. Acrodermatitis continua of Hallopeau (ACH): two cases successfully treated with adalimumab. J Dermatol Treat. 2014;25(6):489-494.

117. Balato N, Gallo L, Balato A, La Bella S, Ayala F. Acrodermatitis continua of Hallopeau responding to efalizumab therapy. J Eur Acad Dermatol Venereol. 2009;23(11):1329-1330.
Psoriasis: Targets and Therapy

\section{Publish your work in this journal}

Psoriasis: Targets and Therapy is international, peer-reviewed, open access journal focusing on psoriasis, nail psoriasis, psoriatic arthritis and related conditions, identification of therapeutic targets and the optimal use of integrated treatment interventions to achieve improved outcomes and quality of life. Visit http://www.dovepress.com/testimonials.php to read real quotes from published authors. 